\title{
GROWTH HORMONE DEFICINCY AND MULTIPLE ENCHONDROMATOSIS (OLLIER DISEASE) IN A BOY WITH SHORT STATURE
}

\author{
Vesselin Boyadzhiev, Boyan Balev', Violeta Iotova \\ Department of Pediatrics and Medical Genetics, ${ }^{1}$ Department of Radiology, \\ Medical University of Varna, Bulgaria
}

\begin{abstract}
We present a boy diagnosed and treated with growth hormone (GH) for isolated GH deficiency. During 2 year follow up he did not catch up in both height and weight. Although there was no skeletal disproportionality, nor any other complaints, his walk began changing and lower limbs deformity appeared (genua vara). Extensive skeletal radiological survey found multiple enchondromatosis (knees, iliac bones) and Ollier disease was diagnosed. There is no specific treatment for this condition, but its presence questions future GH therapy. The poor response to growth hormone treatment and the risk of developing malignant transformation in the future raises the important questions of the real benefits and the possible harms of its maintenance.
\end{abstract}

Keywords: growth hormone deficiency, multiple enchondromatosis, growth failure

\section{INTRODUCTION}

Short stature is one of the most common and most important diagnostic dilemmas in pediatric endocrinology. Besides the "normal" variants - familial short stature and constitutional delay of growth and puberty, the other causes include a variety of different endocrine and metabolic disorders, many syndromes and chronic systemic illnesses as well as numerous rare inborn genetic conditions (1). Among the last ones the skeletal dysplasias (osteochondro-

Address for correspondence:

Department of Paediatrics and Medical Genetics

Medical University of Varna

1 „Hr.Smirnenski“ Blvd., Varna 9010, Bulgaria

e-mail:vessboja@gmail.com

Received: July 25, 2014

Accepted: September 10, 2014 dysplasias) comprise a unique group of more than 450 congenital disorders that could lead to a diverse number of abnormalities of cartilage and bone development (2). We present a boy with confirmed growth hormone $(\mathrm{GH})$ deficiency with poor response to growth hormone treatment due to a coexisting multiple enchondromatosis (Ollier disease). Enchondromas are characterized by the presence of ectopic benign cartilaginous tumors incorporated within the different sites of the mineralized bone tissue. The disorder has several subtypes, no gender bias and can manifest at any age with the symptoms of pain, skeletal deformities, pathological fractures or disproportionate short stature $(3,4)$.

\section{Our patient:}

A 9-year-old boy presented at the clinic with pre- and postnatal growth retardation. He was born from second normal pregnancy of non-consanguineous parents and was delivered 2 weeks before term small for gestational age, with mildly decreased birth 
weight of $2200 \mathrm{~g}$ and length of $43 \mathrm{~cm}$. There was no family history of growth failure or any other genetic, endocrine or systemic disorders. At presentation, the general physical examination did not reveal any significant abnormalities or dysmorphic features, except of a triangular face with a slight asymmetry and a mild pigeon-shaped chest deformity. He had a proportional body appearance with a height of 104 $\mathrm{cm}\left(18 \mathrm{~cm}\right.$ below the $3^{\text {th }}$ percentile, - 5.0 SDS) and weight of $13 \mathrm{~kg}$ ( $9 \mathrm{~kg}$ below 3th percentile, - 7.9 SDS). The standard laboratory blood tests were normal. The hormonal analyses showed thyroxine and cortisol levels in the normal range (TSH $1.25 \mathrm{uIU} / \mathrm{ml}$, FT4 $16.4 \mathrm{pmol} / \mathrm{l}$, cortisol $401.72 \mathrm{nmol} / \mathrm{l})$, but the IGF1 (insulin-like growth factor-1) $52.4 \mu \mathrm{g} / \mathrm{l}$ was below the lower limit (N 74-388). In order to assess the potential of growth hormone production from the pituitary, an insulin tolerance test and a glucagon test were performed showing a maximal peak of growth hormone $6.63 \mathrm{ng} / \mathrm{ml}(\mathrm{N}>10 \mathrm{ng} / \mathrm{ml})$ - a result suggestive of growth hormone deficiency. The patient's bone age, estimated according to Greulich and Pyle method, was also decelerated with more than 4 years, which was also consistent with the diagnosis of growth hormone deficit. There were no bone deformities on the wrists that were followed every 6 months. Finally, after the MRI of the hypothalamuspituitary did not show any abnormalities or lesions, the child was started on growth hormone replacement therapy with gradually increasing doses.

Unfortunately, despite the excellent compliance by the family, during the next couple of years the child's growth velocity did not improve while bone age was progressing and the boy did not manage to catch-up in height (Fig. 1). Instead of this, a progressive development of an O-shaped deformity of his legs began to attract the attention. There was no pain or any other complaints. At the end of our follow-up of more than 3 years, the boy's gait became waddling and his appearance more and more disproportionate. At 12 years of age the intercondylar distance (the distance between the medial femoral condyles of his knees) was $10 \mathrm{~cm}$ (reference $<6 \mathrm{~cm}$ ) (5). At the same time, his sitting height to height ratio became 0.55 $\mathrm{cm}(>+2.5 \mathrm{SD})$ and his lower segment to upper segment ratio was $1.22->+2.5 \mathrm{SD}$ (Fredriks et al, 2005). These measurements proved the presence of a signif-

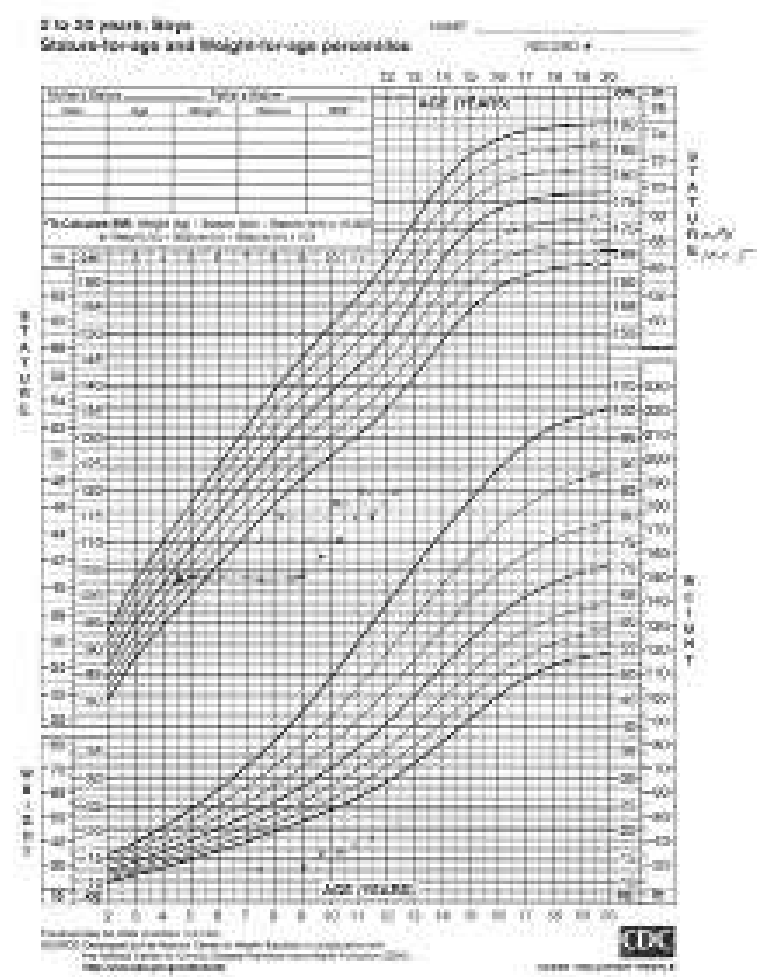

Fig. 1. Patient's growth chart

icant disproportion with shortening of the leg length - a finding requiring further investigations (Fig. 2).

In the region of both knees roentgenograms showed symmetrical and predominantly medial metaphyseal widening due to clusters of multiple, radiolucent, homogenous enchodromatous lesions and formation of genua vara. Multiple strip-like longitudinal small foci of osteosclerosis were visualized. The metaphyses' outline was not clear-cut. Similar changes were found in the iliac bones too, but the arms, the hands, the skull and the vertebral bodies were unaffected (Fig. 3-5). There were pseudo epiphyses at the basis of the second metacarpal bones bilaterally. The co-presence of multiple enchondromatosis or Ollier disease was diagnosed.

\section{DISCUSSION}

Benign cartilaginous tumors can grow inside the bone as endosteal tumors - enchondromas or as osteochodromas (exostoses) that grow on bone surface. They are a result from different types of deregulation of the normal chondrogenesis and bone formation $(3,4)$. The main skeletal growth instrumentality is the endochondral bone ossification that takes 

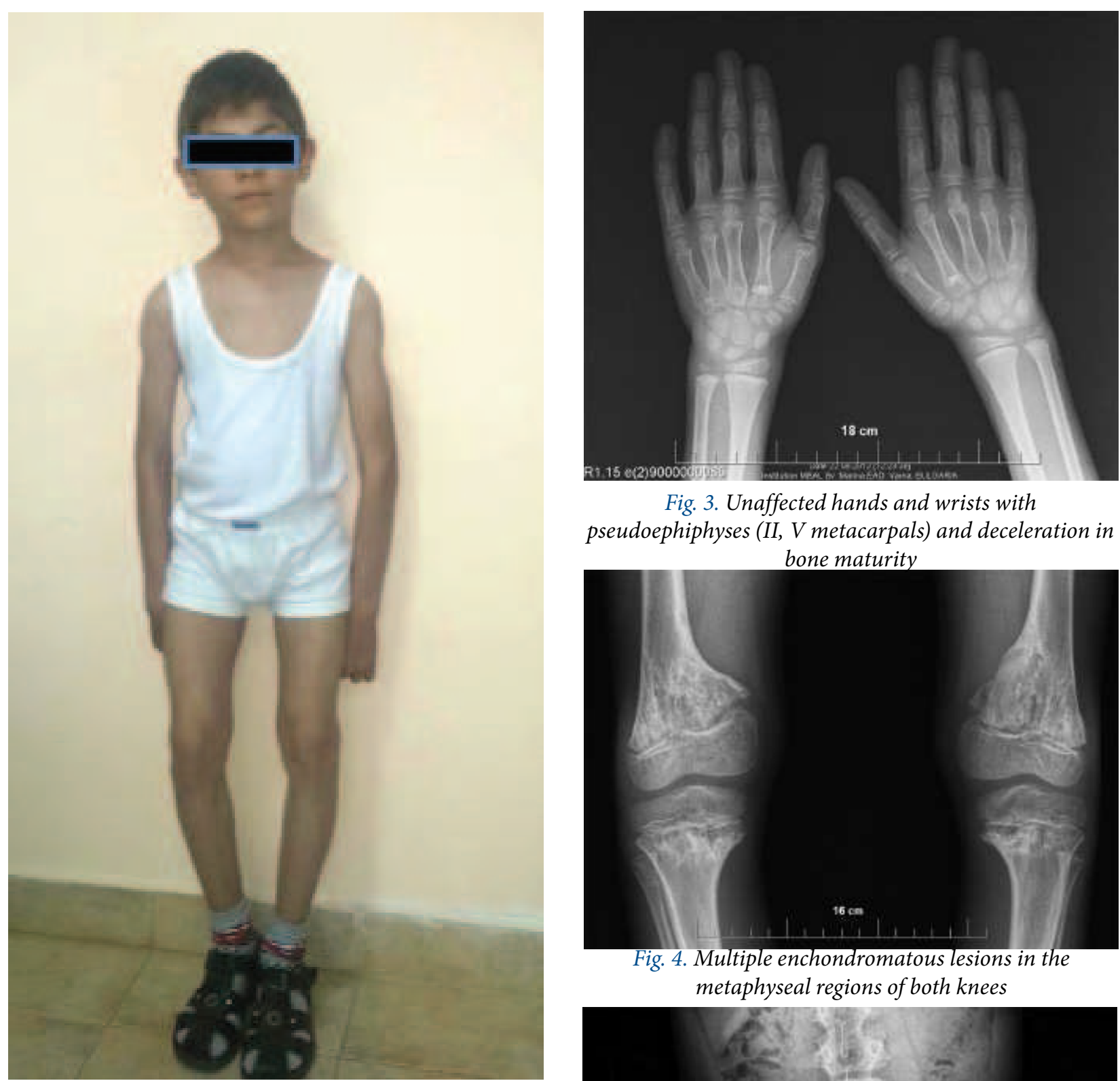

Fig. 3. Unaffected hands and wrists with pseudoephiphyses (II, V metacarpals) and deceleration in bone maturity

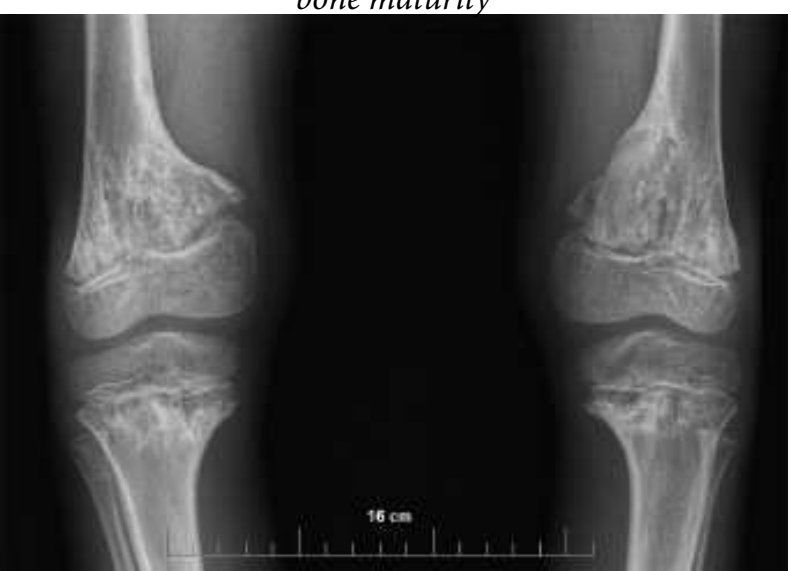

Fig. 4. Multiple enchondromatous lesions in the metaphyseal regions of both knees

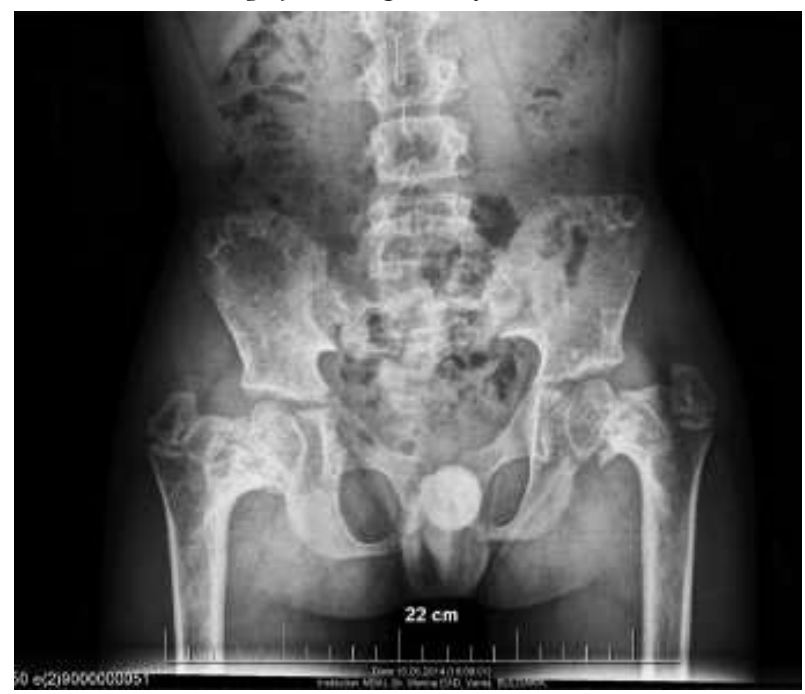

Fig. 5. Enchondromatous changes in iliac bones 
Ultimately, the hypertrophic chondrocytes calcify their surrounding extracellular matrix and undergo apoptosis thus becoming a part of the mineralized template that serves as a scaffold for the subsequent bone formation by the invading osteoblasts $(3,4)$.

The growth and the differentiation of the cartilaginous cells in the epiphyseal growth plates are tightly regulated by multiple endocrine, paracrine and local signaling molecules including bone-morphogenic proteins (BMPs), tumor-growth factor beta (TGF $\beta$ ), insulin-like growth factor-1 (IGF-1), indian hedgehog (IHH), thyroid and sex hormones, parathyroid hormone-related peptide (PTHrP) and Wnt/ $\beta$-catenin pathway $(3,4)$.

Enchondromas themselves are a heterogeneous group of non-hereditary, sporadic skeletal disorders characterized by the presence of hyaline cartilage tumors located nearby the growing parts of the affected bones. Usually enchondromas are solitary, benign and asymptomatic. On x-rays they present as linear or oval-shaped intraosseous osteolytic loci with well-defined borders. Sometimes a light trabeculation may be also visible. Although the typical location is the medulla of the long tubular bones, especially the metaphyseal zones, flat bones could be also involved. Histologically the lesions show abundant hyaline cartilage matrix with low cellularity, often with zones of calcification. Initially the enchondromas appear close to the growth plate cartilage where the endochondral bone ossification takes place and then migrate towards the diaphysis $(4,6)$.

When multiple, the lesions are generally defined as Enchondromatosis that encompasses several different subtypes of which Ollier disease, Maffuci syndrome and metachondromatosis are the most common ones.

First described in 1889, Ollier disease (OMIM $166000)$ is the most common subtype with estimated prevalence of 1/100 000 (7). It is a non-familial disorder with only a few familial cases that have been reported. The diagnosis is mostly encountered in childhood and both sexes are equally affected. The clinical manifestation often appears during the first decade of life and entirely depends on the size, number and location of the tumors. The typical evolution leads to the development of bone deformities, limb shortening with or without pathological frac- tures. Lesions are often asymmetrically distributed and may involve any part of the skeleton, although the vertebral bodies and the skull are very rarely affected. Because of the irregular distribution of the lesions, it is widely accepted that the abnormalities of the bone formation might be a result of a post-zygotic somatic mutations that lead to mosaicism $(4,6,7)$. In small percentage of the patients, a mutation is found in the gene for PTH1R, the receptor for parathyroid hormone-related peptide (PTHrP) - one of the key signaling molecules that control the normal chondrocyte differentiation in the growth plates (8).

The presence of enchondromas in association with soft-tissue cavernous haemangiomas is termed Maffuci syndrome, OMIM 614569. In these cases the lesions are typically located in the hands and feet $(6,9)$.

The malignant transformation towards secondary central chondrosarcoma is the major complication and can occur in up to $30-40 \%$ of the patients with Ollier disease and even higher for patients with Maffucci syndrome. More interestingly, non-skeletal tumors - gliomas, acute myeloid leucemia, abdominal tumors, have also been occasionally reported (4, 10). Recent genetic studies discovered that up to approximately $80 \%$ of patients with Ollier disease and Maffucci syndrome carry in their tumors a somatic mutation in isocitrate dehydrogenase gene-1 (IHD-1) and IHD-2. The mutations in both genes result in a defect of the metabolism of $\alpha$-ketoglutarate with the overproduction of molecules with oncogenic potential like 2-hydroxyglutarate that can change the histone methylation and the expression of several oncogenes $(10,12)$.

Metachondromatosis, OMIM 156250, the third major form of enchondromatosis, is characterized by the combination of enchondromas and osteochondromas. Although only about 30 cases have been reported, it is clear that the disease shows an autosomal dominant pattern of inheritance. In 2010 Sobreira and in 2011 Bowen discovered that loss-of-function mutations in PTPN11 gene (12q24) are linked to the disease. PTPN11 gene encodes a protein tyrosine phosphatase SHP2 that is involved in a variety of signaling pathways. According to the data from recent mice models studies, SHP2 seems to play an important role in cartilage development and SHP2-deficient mice show delayed terminal differentiation of 
the hypertrophic chondrocytes and ectopic chondrogenesis $(6,13)$.

Hereditary multiple osteochondromatosis is another form of generalized exostosis which is caused by mutations in EXT1 (8q24.1) and EXT2 (11p13) genes. Approximately in $60 \%$ of the cases the disease is inherited from one of the parents and in the rest of the patients it is due to a de novo mutation. Both EXT genes encode transmembrane glycosyltransferases exostosin-1 and exostosin-2, involved in the production of heparin sulfate (14).

To the best of our knowledge, there is no published case in the literature with the combined presence of Ollier disease and growth hormone deficiency. The bone disease diagnosis poses the question whether the $\mathrm{GH}$ treatment should be stopped, especially in the view of the increased malignancy risk in such patients. Since there is no guidance in the literature, our current decision is to stop for 6 months and re-test for GH deficiency and possible sequels of its shortage (lipid metabolism, muscle tonus, etc.). The final decision whether to continue or not with the GH treatment will be then discussed extensively with the family.

\section{CONCLUSIONS}

We present a rare case of short stature due to the combination of isolated growth hormone deficiency and a rare type of underlying osteochodrodysplasia. The poor response to growth hormone treatment and the risk of developing malignant transformation in the future raises the important questions of the real benefits and the possible harms of the maintenance of such a therapy.

\section{REFERENCES}

1. Raine J. E., M. Donaldson et al. Pediatric endocrinology and diabetes in children, 2nd edition 2006, chapter 3: Short stature, 42-63

2. Alanay Y., R. S. Lachman. A review of the principles of radiological assessment of skeletal dysplasias. J Clin Res Pediatr Endocrinol, Dec 2011; 3(4): 163-178

3. Camacho-Hubner C., O. Nilsson, L. Savendahl. Cartilage and bone development and its disorders. Endocr. Dev., Karger. 2011, chapter 3: Physiology of bone, 32-48
4. Herget G. W., P. Strohm, C. Rottenburger et al. Insights into Enchondroma, Enchondromatosis and the risk of secondary Chondrosarcoma. Review of the literature with an emphasis on the clinical behaviour, radiology, malignant transformation and the follow up. Neoplasma 2014, 61 (4), 365-378

5. Ozkan B. Nutritional rickets. J Clin Res Pediatr Endocrinol. Dec 2010; 2(4), 137-143

6. Pansuriya T. C., H. Kroon, J. Bovee. Enchondromatosis: insights on the different subtypes. Int J Clin Exp Pathol 2010, 3 (6), 557-569

7. Silve C., H. Jüppner. Ollier disease. Orphanet Journal of Rare Diseases 2006, 1:37

8. Couvineau A., V. Wouters, G. Bertrand et al. PTHR1 mutations associated with Ollier disease result in receptor loss of function. Human Molecular Genetics, 2008, Vol. 17, No. 18, 2766-2775

9. Mulliken J., P. Burrows, S. Fishman. Mulliken and Young's Vascular Anomalies: Hemangiomas and Malformations. Oxford University Press, USA; 2nd edition 2013; chapter 9, 349

10. Dang L., S. Jin, SM Su. IDH mutations in glioma and acute myeloid leukemia. Trends Mol Med. 2010 Sep; 16(9), 387-397

11. Amary MF, K. Bacsi, F. Maggiani et al. IDH1 and IDH2 mutations are frequent events in central chondrosarcoma and central and periosteal chondromas but not in other mesenchymal tumours. J Pathol. 2011 Jul; 224(3), p. 334-343. doi: 10.1002/path.2913. Epub 2011 May 19.

12. Pansuriya TC, R. van Eijk, P. d'Adamo $P$ et al. Somatic mosaic IDH1 and IDH2 mutations are associated with enchondroma and spindle cell hemangioma in Ollier disease and Maffucci syndrome., Nat Genet. 2011 Nov 6; 43(12), 1256-61.

13. Yang W., B. Neel. From an orphan disease to a generalized molecular mechanism PTPN11 lossof-function mutations in the pathogenesis of metachondromatosis. Rare Diseases 1, e26657; 2013, http://dx.doi.org/10.4161/rdis.26657

14. Bovee J. Multiple osteochondromas. Orphanet J Rare Dis. 2008; 3: 3. doi: 10.1186/1750-1172-3-3 